\title{
Physical and Electrical Characteristics of Carbon Nanotube Network Field-Effect Transistors Synthesized by Alcohol Catalytic Chemical Vapor Deposition
}

\author{
Chin-Lung Cheng, ${ }^{1}$ Chien-Wei Liu, ${ }^{2}$ Bau-Tong Dai, ${ }^{3}$ and Ming-Yen Lee ${ }^{4}$ \\ ${ }^{1}$ Department of Electro-Optical Engineering, National Formosa University, Yunlin 63201, Taiwan \\ ${ }^{2}$ Department of Mechanical Engineering, National Yunlin University of Science and Technology, Yunlin 64054, Taiwan \\ ${ }^{3}$ National Nano Device Laboratories, National Applied Research Laboratories, Hsinchu 30078, Taiwan \\ ${ }^{4}$ Institute of Materials Science and Green Energy Engineering, National Formosa University, Yunlin 63201, Taiwan \\ Correspondence should be addressed to Chien-Wei Liu, liucw@yuntech.edu.tw \\ Received 15 March 2011; Revised 2 May 2011; Accepted 12 May 2011 \\ Academic Editor: Gong Ru Lin
}

Copyright ( $\odot 2011$ Chin-Lung Cheng et al. This is an open access article distributed under the Creative Commons Attribution License, which permits unrestricted use, distribution, and reproduction in any medium, provided the original work is properly cited.

Carbon nanotubes (CNTs) have been explored in nanoelectronics to realize desirable device performances. Thus, carbon nanotube network field-effect transistors (CNTNFETs) have been developed directly by means of alcohol catalytic chemical vapor deposition (ACCVD) method using Co-Mo catalysts in this work. Various treated temperatures, growth time, and Co/Mo catalysts were employed to explore various surface morphologies of carbon nanotube networks (CNTNs) formed on the $\mathrm{SiO} / \mathrm{n}$-type $\mathrm{Si}(100)$ stacked substrate. Experimental results show that most semiconducting single-walled carbon nanotube networks with 5-7 nm in diameter and low disorder-induced mode ( $D$-band) were grown. A bipolar property of CNTNFETs synthesized by ACCVD and using $\mathrm{HfO}_{2}$ as top-gate dielectric was demonstrated. Various electrical characteristics, including drain current versus drain voltage $\left(I_{d}-V_{d}\right)$, drain current versus gate voltage $\left(I_{d}-V_{g}\right)$, mobility, subthreshold slope (SS), and transconductance $\left(G_{m}\right)$, were obtained.

\section{Introduction}

Carbon nanotube field-effect transistors (CNTFETs) have been explored in nanoelectronics to realize desirable device characteristics [1-11]. Both n-type and p-type single-walled carbon nanotube (SWCNT) field-effect transistors (FETs) with top-gate electrodes in the conventional metal-oxidesemiconductor field-effect transistor (MOSFET) structures were demonstrated [1]. Two methods, including conventional doping and annealing metal/carbon nanotubes (CNTs) contact in vacuum, were used for the CNTFETs conversion from $\mathrm{p}$ - to n-type devices [2]. Moreover, the fabrication of the n-type CNTFET by Al-doped CNTs as channel was also achieved [12]. The primary potential advantage of CNTs is their very high carrier mobility $(7.9 \times$ $10^{4} \mathrm{~cm}^{2} / \mathrm{V}$-s) [13]. However, one of challenges of CNTs to be viable in high-performance FETs is the requirement for processes that provide each CNTs placed in a desired location and direction [14]. Recently, an architecture based on the assembly of two- and three-dimensional networks of SWNTs using chemical vapor deposition (CVD) was demonstrated [15]. The field-effect mobility of random networks of SWCNT as thin-film transistor can exceed $100 \mathrm{~cm}^{2} / \mathrm{V}-\mathrm{s}$ [16]. SWCNT random network thin film transistor with a $10^{5}$ of on/off ratio and a $\sim 8 \mathrm{~cm}^{2} / \mathrm{C}$-s of field-effect mobility was demonstrated using water-assisted plasma-enhanced CVD (PECVD) [17]. Although various methods were used to synthesize the carbon nanotube networks (CNTNs), some electrical characteristics of CNTNs fabricated by alcohol catalytic CVD (ACCVD) remain not totally understood. We, therefore, attempt to explore some characteristics to gain better physical and electrical insights into the properties of CNTN field-effect transistors (CNTNFETs).

\section{Experimental Methods}

CNTNFETs with top-gated structures were fabricated on (100-) oriented n-type silicon wafers. The substrate consists 


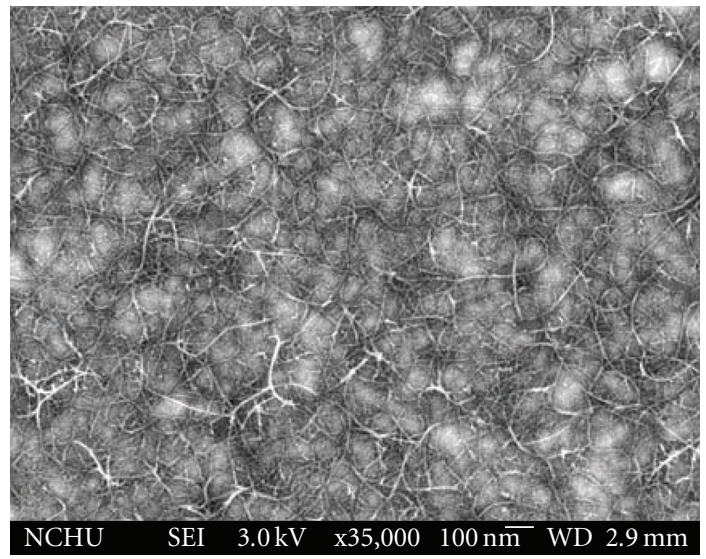

(a)

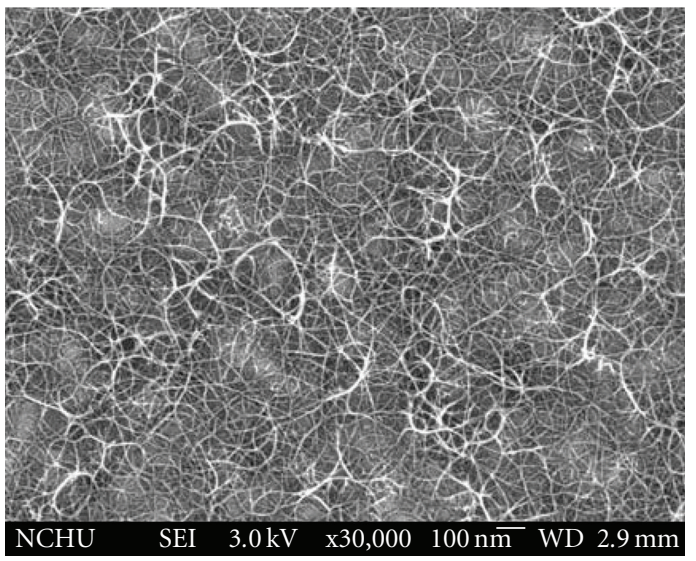

(c)

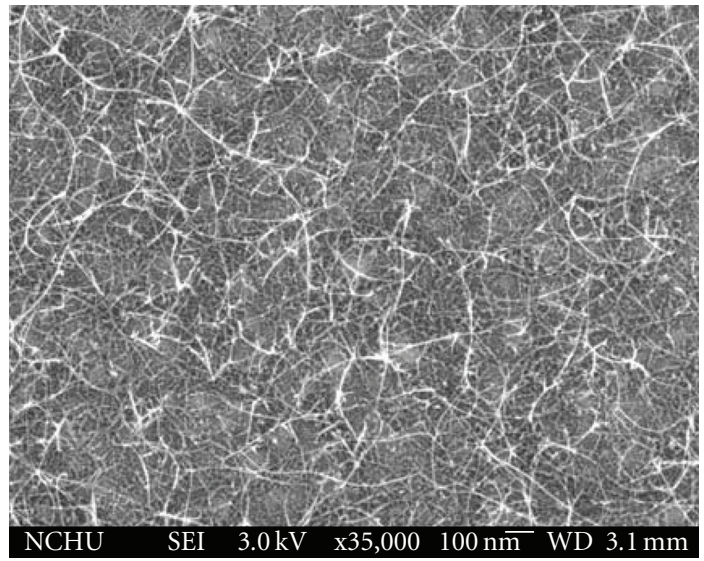

(b)

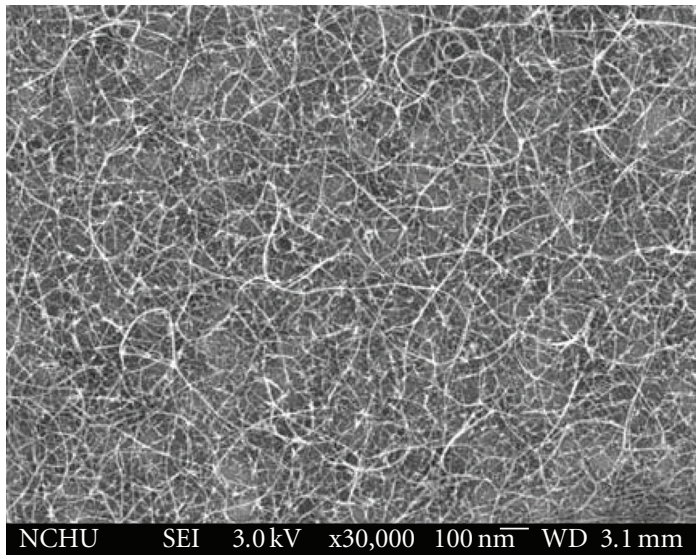

(d)

Figure 1: Plane view of SEM morphology of random carbon nanotube networks (CNTNs) formed on the $\mathrm{SiO} \mathrm{O}_{2} / \mathrm{n}$-type $\mathrm{Si}(100)$ stacked substrate. The substrate consists of a highly doped n-type $\operatorname{Si}(100)$ wafer with an arsenic doping concentration of $N_{D}>10^{20} \mathrm{~cm}^{-3}$. The growth conditions were carried out at $750^{\circ} \mathrm{C}$ in the alcohol ambient for (a) 5, (b) 10, (c) 15, and (d) 20 min; respectively, and the partial pressure was achieved in 10 Torr. A Co/Mo acetate was premixed at $\mathrm{Co}: \mathrm{Mo}=0.1: 0.1 \mathrm{wt} \%$ and dissolved in ethanol with sonication for 8 hour.

of a highly doped n-type $\mathrm{Si}(100)$ wafer with an arsenic doping concentration of $N_{D}>10^{20} \mathrm{~cm}^{-3}$. Prior to $\mathrm{SiO}_{2}$ growth, all wafers were cleaned through a wet cleaning process (APM/HPM/DHF), using an $\mathrm{NH}_{4} \mathrm{OH} / \mathrm{H}_{2} \mathrm{O}_{2} / \mathrm{H}_{2} \mathrm{O}$ mixture (APM) in a ratio of $1: 4: 20$ (volume) at $75^{\circ} \mathrm{C}$ and an $\mathrm{HCl} / \mathrm{H}_{2} \mathrm{O}_{2} / \mathrm{H}_{2} \mathrm{O}$ mixture (HPM) in a ratio of $1: 1: 6$ (volume) at $75^{\circ} \mathrm{C}$, to remove residues and contaminants. The dipping time in all processes was $10 \mathrm{~min}$. Diluted HF (DHF), with an HF: $\mathrm{H}_{2} \mathrm{O}$ ratio of $1: 100$ (volume), was used to remove native oxide. Following the wet processes, all of the samples were rinsed in deionized water for $10 \mathrm{~min}$. Then, the $\mathrm{SiO}_{2}$ layers with $100 \mathrm{~nm}$ thicknesses measured by the spectroscopic ellipsometry were thermally grown on the cleaned wafers. The $\mathrm{SiO}_{2}$ layers were prepared by the dry thermal oxidation in $\mathrm{O}_{2}$ at $925^{\circ} \mathrm{C}$. To obtain a hydrophilic surface, all $\mathrm{SiO}_{2} / \mathrm{n}-\mathrm{Si}(100)$ stacked substrates were treated through a wet cleaning process (APM/HPM). Next, a Co acetate $\left[\left(\mathrm{CH}_{3} \mathrm{CO}_{2}\right)_{2} \mathrm{Co}-4 \mathrm{H}_{2} \mathrm{O}\right]$ and a Mo acetate $\left[\left(\mathrm{CH}_{3} \mathrm{COOH}\right)_{2} \mathrm{Mo}\right]$ were premixed at (a) $\mathrm{Co}: \mathrm{Mo}=0.1: 0.1 \mathrm{wt} \%$, (b) $\mathrm{Co}: \mathrm{Mo}=0.05: 0.05 \mathrm{wt} \%$, and (c) $\mathrm{Co}: \mathrm{Mo}=0.02: 0.02 \mathrm{wt} \%$, as well as dissolved in ethanol with sonication for 8 hours and then the Co/Mo catalysts were dip-coated on the $\mathrm{SiO}_{2}$ surface. After drying at the room temperature, all samples were put into ACCVD chamber and were calcined from the room temperature to $400^{\circ} \mathrm{C}$ for $10 \mathrm{~min}$. Then, the temperature was risen from 400 to (a) 650 , (b) 700 , and (c) $750^{\circ} \mathrm{C}$ for 30 min with a mixed $\mathrm{Ar} / \mathrm{NH}_{3}$ gases flow of 200/30 SCCM (SCCM denotes cubic centimeter per minute at STP), and a pressure is about 1015 torr. Under the process temperature of (a) 650, (b) 700, and (c) $750^{\circ} \mathrm{C}$, the $\mathrm{Ar} / \mathrm{NH}_{3}$ mixed gases were stopped, and the heated alcohol vapor was supplied into the quartz tube with a process pressure of 10 Torr for (a) 5, (b) 10, (c) 15 , and (d) $20 \mathrm{~min}$, respectively. After active region (AR) definition lithography, outer CNTN of AR was etched by an $\mathrm{SF}_{6}=50 \mathrm{sccm}$ ambient with a radio frequency (RF) power of $50 \mathrm{~W}$ and following photoresist (PR) removal. Then, the source/drain electrodes using $\mathrm{Au}$ (bottom)/Al (top) stacked films of $20 / 300 \mathrm{~nm}$ thick were deposited via sputtering and were patterned by lift-off technique. Then, the $\mathrm{HfO}_{2}$ layers 
with $30.0 \mathrm{~nm}$ thicknesses measured by the deposited sensor were deposited using reactive $\mathrm{dc}$ magnetron sputtering of 99.95\% pure $\mathrm{Hf}$ targets in an $\mathrm{Ar}=24 \mathrm{sccm}$ ambient with a power of $\mathrm{Hf}$ target at RF power of $30 \mathrm{~W}$. Subsequently, postdeposition annealing (PDA) using furnace annealing was performed in $\mathrm{O}_{2}$ gas for $30 \mathrm{~min}$ at $450^{\circ} \mathrm{C}$. A metal gate electrode with a $500 \mathrm{~nm}$ Al film was deposited via sputtering and was patterned by the lithography. Various physical properties of CNTNs were analyzed by Raman spectrometry, scanning electron microscope (SEM), and high-resolution transmission electron microscope (HRTEM), respectively. Various electrical characteristics of CNTNFETs were evaluated by the HP 5270B instrument.

\section{Results and Discussion}

Various treated temperatures, growth time, and Co/Mo catalysts were employed to explore various surface morphologies of CNTNs formed on the $\mathrm{SiO}_{2} / \mathrm{n}$-type $\mathrm{Si}(100)$ stacked substrate. The substrate consists of a highly doped n-type $\mathrm{Si}(100)$ wafer with an arsenic doping concentration of $N_{D}>$ $10^{20} \mathrm{~cm}^{-3}$. Various SEM plane views of CNTNs formed on the $\mathrm{SiO}_{2} / \mathrm{n}$-type $\mathrm{Si}(100)$ stacked substrates were shown in Figures 1-3. The growth conditions were carried out at $750^{\circ} \mathrm{C}$ in the alcohol ambient for (a) 5, (b) 10 , (c) 15 , and (d) $20 \mathrm{~min}$; respectively, and the partial pressure was achieved in 10 Torr as shown in Figure 1. A Co/Mo acetate was premixed at $\mathrm{Co}: \mathrm{Mo}=0.1: 0.1 \mathrm{wt} \%$ and dissolved in ethanol with sonication for 8 hours. It can be seen that dispersed CNTNs were formed on the $\mathrm{SiO}_{2} /$ n-type $\mathrm{Si}(100)$ stacked substrate resulting from short growth time as shown in Figure 1(a). On the contrary, the dense CNTNs were demonstrated using long growth time as shown in Figure 1(d). Thus, the results suggest that the densities of CNTNs increase with increasing time of growth.

To scrutinize the effects of various $\mathrm{wt} \%$ of $\mathrm{Co} / \mathrm{Mo}$ catalysts on characteristics of CNTNs, various $\mathrm{Co} / \mathrm{Mo}$ acetates were premixed at (a) Co: $\mathrm{Mo}=0.1: 0.1 \mathrm{wt} \%$, (b) $\mathrm{Co}: \mathrm{Mo}=0.05: 0.05 \mathrm{wt} \%$, and (c) $\mathrm{Co}: \mathrm{Mo}=0.02: 0.02 \mathrm{wt} \%$, respectively, as shown in Figure 2. The growth conditions were carried out at $750^{\circ} \mathrm{C}$ in the alcohol ambient for $10 \mathrm{~min}$. Compared with high concentration of the Co/Mo catalysts, the dispersed CNTNs were formed by the Co/Mo catalysts with low concentration. This could be due to the dispersion of the Co/Mo catalysts with low concentration. Therefore, the results indicate that the densities of CNTNs decrease with decreasing wt $\%$. Moreover, the effects of various treated temperatures on the densities of CNTNs are important issues. Thus, the growth conditions were performed at (a) 750 , (b) 700 , and (c) $650^{\circ} \mathrm{C}$, respectively, in the alcohol ambient for $10 \mathrm{~min}$ and shown in Figure 3. A Co/Mo acetate was premixed at $\mathrm{Co}: \mathrm{Mo}=0.1: 0.1 \mathrm{wt} \%$. The experimental results demonstrate that the densities of CNTNs increase with increasing growth temperature.

To probe diameter of CNTNs, the TEM analysis was adopted. According to the top morphology of TEM analysis, a single-walled CNTN with $5-7 \mathrm{~nm}$ in diameter was grown as shown in Figure 4. Experimental results show that CNTs with various diameters were crisscrossed through another

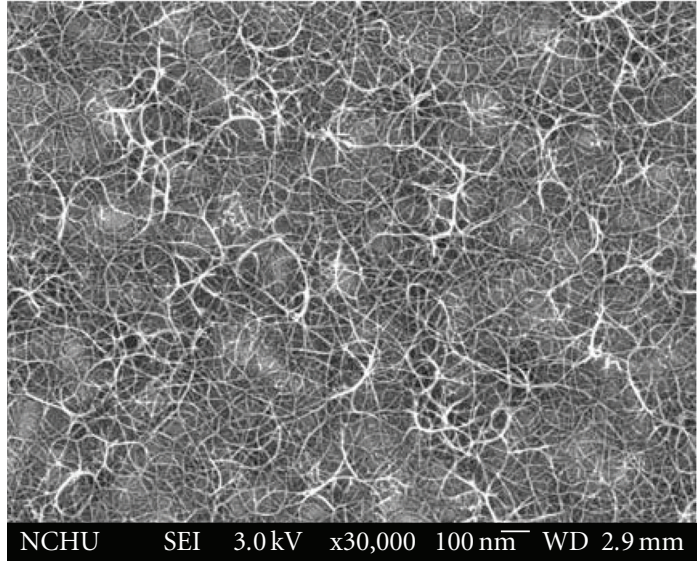

(a)

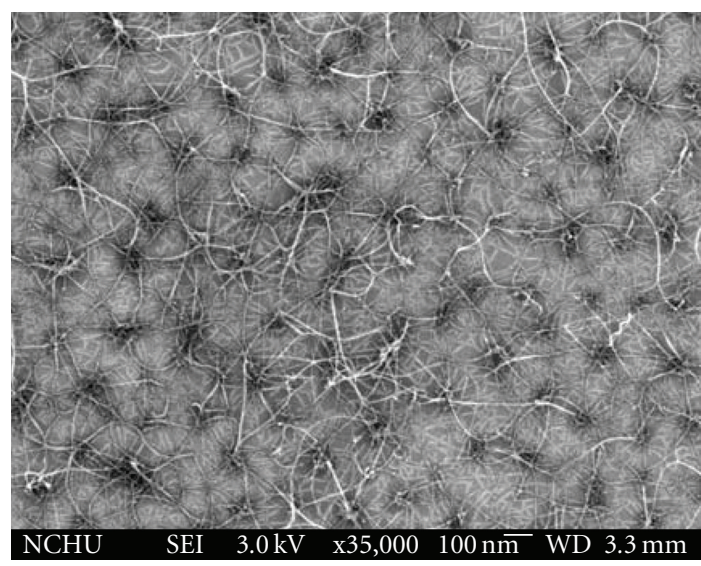

(b)

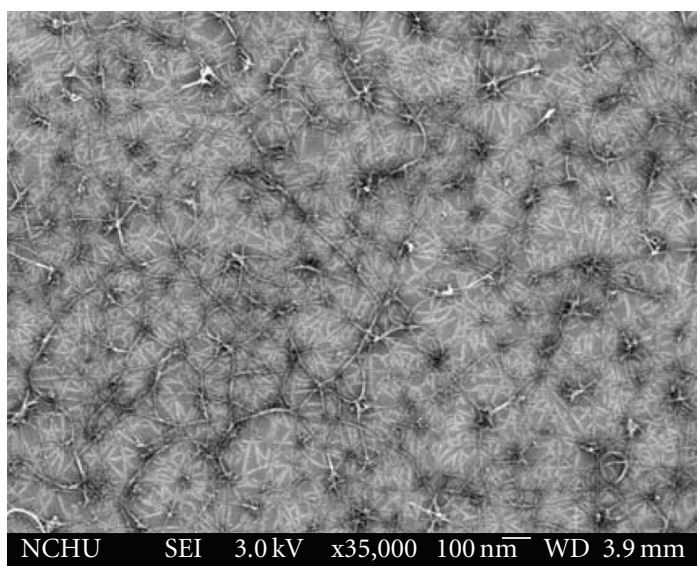

(c)

FIgure 2: Plane view of SEM morphology of CNTNs formed on the $\mathrm{SiO}_{2} /$ n-type $\mathrm{Si}(100)$ stacked substrate. The growth conditions were carried out at $750^{\circ} \mathrm{C}$ in the alcohol ambient for $10 \mathrm{~min}$, and the partial pressure was achieved in 10 Torr. Various $\mathrm{Co} / \mathrm{Mo}$ acetate were premixed at (a) Co: $\mathrm{Mo}=0.1: 0.1 \mathrm{wt} \%$, (b) Co: Mo $=0.05: 0.05 \mathrm{wt} \%$, and (c) Co: $\mathrm{Mo}=0.02: 0.02 \mathrm{wt} \%$, respectively. Then, all Co/Mo catalysts were dissolved in ethanol with sonication for 8 hours. 


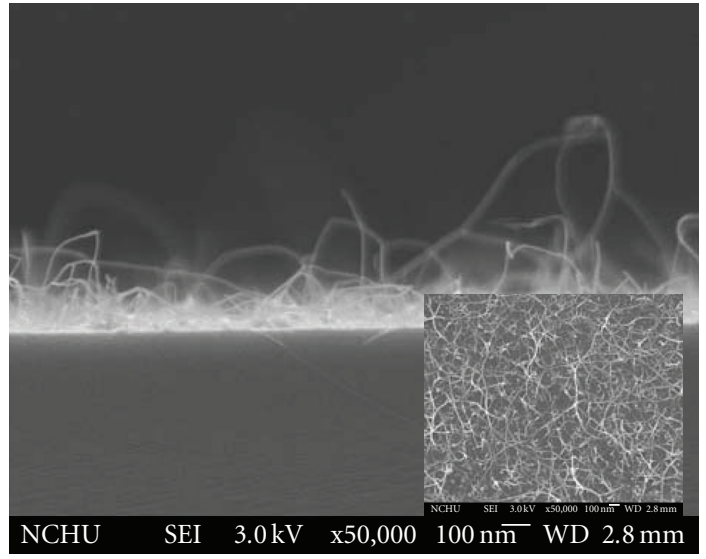

(a)

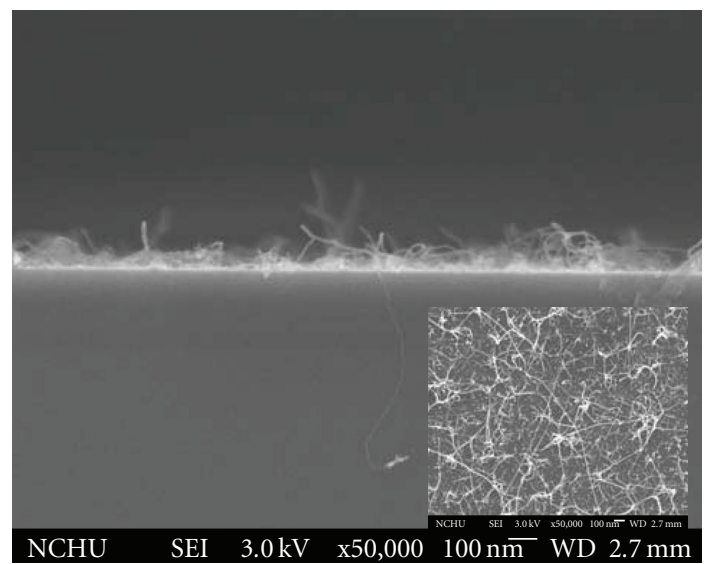

(b)



(c)

FIGURE 3: Cross-sectional view of SEM morphology of CNTNs formed on the $\mathrm{SiO}_{2} /$ n-type $\mathrm{Si}(100)$ stacked substrate. Various plane views were also shown in the inset of figure. The growth conditions were carried out at (a) 750 , (b) 700 , and (c) $650^{\circ} \mathrm{C}$ in the alcohol ambient for $10 \mathrm{~min}$, and the partial pressure was achieved in 10 Torr. A Co/Mo acetate was premixed at $\mathrm{Co}: \mathrm{Mo}=0.1: 0.1 \mathrm{wt} \%$ and dissolved in ethanol with sonication for 8 hours.

one densely. Thus, according to the results of Figures 1-4, the CNTNs synthesized at $750^{\circ} \mathrm{C}$ in the alcohol ambient for

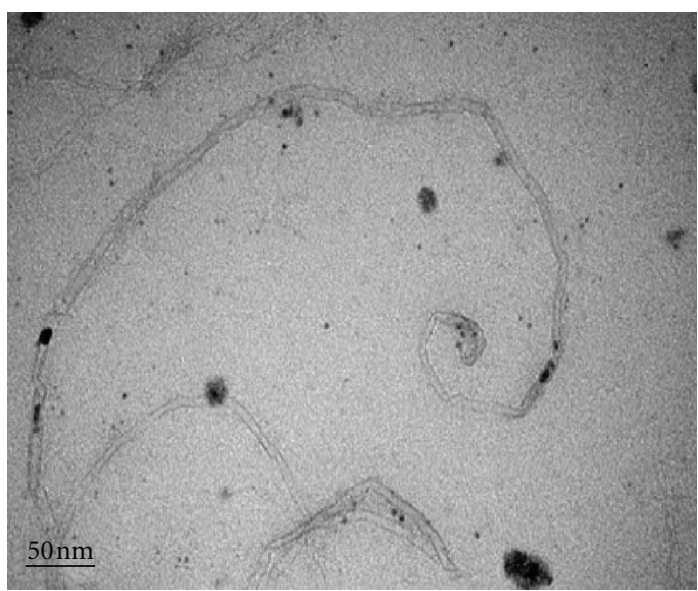

Figure 4: Plane view of TEM morphology of CNTNs was formed on the $\mathrm{SiO}_{2} /$ n-type $\mathrm{Si}(100)$ stacked substrate. The growth conditions were carried out at $750^{\circ} \mathrm{C}$ in the alcohol ambient for $10 \mathrm{~min}$, and the partial pressure was achieved in 10 Torr. A Co/Mo acetate was premixed at $\mathrm{Co}: \mathrm{Mo}=0.1: 0.1 \mathrm{wt} \%$ and dissolved in ethanol with sonication for 8 hours.



FIGURE 5: Raman spectra of as-grown CNTNs deposited on the $\mathrm{SiO}_{2} /$ n-type $\mathrm{Si}(100)$ substrate measured with $633 \mathrm{~nm}$ excitation and energy of $1.96 \mathrm{eV}$.

10 min under the $\mathrm{Co}: \mathrm{Mo}=0.1: 0.1 \mathrm{wt} \%$ were used to prepare the CNTNFET.

To demonstrate various physical characteristics of as-grown CNTNs, Raman spectra of as-grown CNTNs deposited on the $\mathrm{SiO}_{2} / \mathrm{n}$-type $\mathrm{Si}(100)$ substrate measured with $633 \mathrm{~nm}$ excitation and energy of $1.96 \mathrm{eV}$ were shown in Figure 5. For isolated semiconducting SWNT, the Ramanallowed tangential modes ( $G$ mode) are labeled $G^{+}$and $G^{-}$ at Raman frequency $(\omega)$ of $1592\left(\omega_{G^{+}}\right)$and $1570\left(\omega_{G^{-}}\right)$ $\mathrm{cm}^{-1}$, respectively [18]. Thus, the results suggest that asgrown CNTNs synthesized by ACCVD are semiconducting 

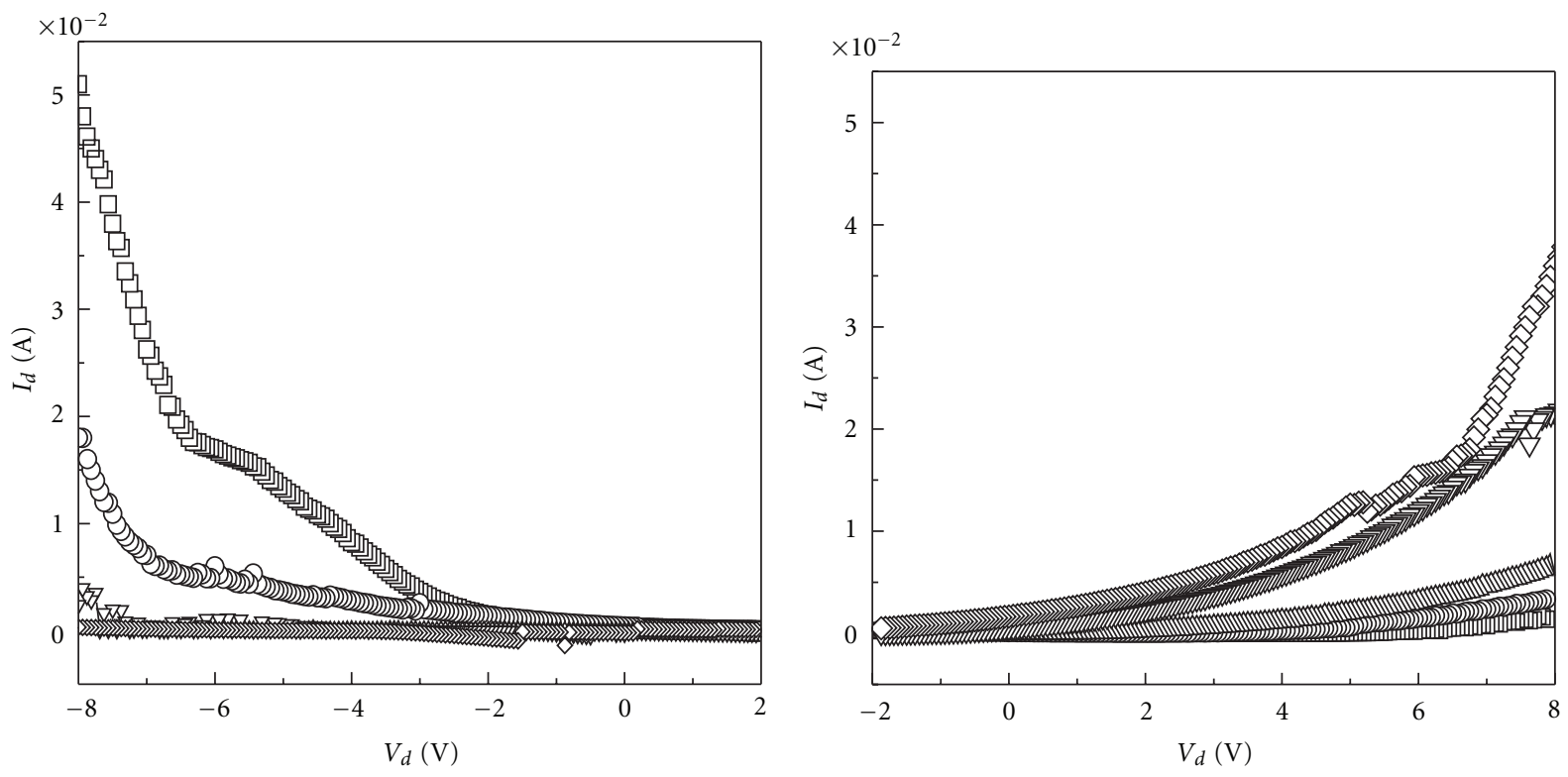

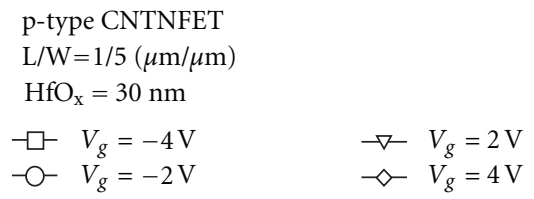

(a)

$$
\begin{aligned}
& \text { n-type CNTNFET } \\
& \mathrm{L} / \mathrm{W}=1 / 5(\mu \mathrm{m} / \mu \mathrm{m}) \\
& \mathrm{HfO}_{\mathrm{x}}=30 \mathrm{~nm} \\
& \prec \quad V_{g}=4 \mathrm{~V} \\
& \neg-V_{g}=2 \mathrm{~V}
\end{aligned}
$$$$
\triangle-V_{g}=0 \mathrm{~V}
$$

(b)

FIGURE 6: Drain current versus drain voltage $\left(I_{d}-V_{d}\right)$ characteristics of (a) p-CNTNFET and (b) n-CNTNFET with HfO2 of 30 nm as gate dielectric. The channel length and width of CNTNFETs were 1 and $5 \mu \mathrm{m}$, respectively.

SWNTs. This is further demonstrated by using the lowfrequency peak measurement. The low-frequency peak is given by $\omega_{G^{-}}=\omega_{G^{+}}-C / d^{2}$, where $d$ is the diameter of $\mathrm{CNT}$, with $C$ being different for metallic $\left(C \sim 79.5 \mathrm{~cm}^{-1} \mathrm{~nm}^{2}\right)$ and semiconducting $\left(C \sim 47.7 \mathrm{~cm}^{-1} \mathrm{~nm}^{2}\right.$ ) SWNTs [19]. Since the results show that the $C$ value of CNTNs synthesized by ACCVD is to be around $57 \mathrm{~cm}^{-1} \mathrm{~nm}^{2}$, most semiconducting CNTNs were demonstrated. A little metallic nanotubes could be included in the CNTNs synthesized by ACCVD. Moreover, it has been reported that the intensity ratio between the two most intense features is in the range $0.1<I \omega_{G^{-}} / I \omega_{G^{+}}<0.3$ for most of the isolated SWNTs (90\%) [19]. In this work, the value of $I \omega_{G}{ }^{-} / I \omega_{G}{ }^{+}$is to be around 0.214 , indicating that the CNTNs with $90 \%$ SWNTs were demonstrated. Furthermore, the defects in CNTs are characterized by $G_{\mathrm{CNT}}=I_{G} /\left(I_{D}+I_{G}\right)$, where $I_{G}$ is the intensity of $G$ mode, $I_{D}$ is the intensity of disorder-induced mode (D band). The value of $G_{\text {CNT }}$ is estimated to be around 0.92, indicating that the CNTNs with low defects were synthesized by ACCVD.

Figure 6 shows the output characteristics, drain current versus drain voltage $\left(I_{d}-V_{d}\right)$, of p-CNTNFET and nCNTNFET consisting of an $\mathrm{HfO}_{2}$ of $30 \mathrm{~nm}$ as top-gate dielectric for several values of the gate voltage. The channel length and width of CNTNFETs was 1 and $5 \mu \mathrm{m}$, respectively. At $V_{g}$ near $0 \mathrm{~V}$, the $I_{d}$ current of devices were to be around
0 , indicating that the devices were off-status. For $V_{g}>0$ and $V_{d}>0$, the behavior of $I_{d}-V_{d}$ curves were similar to that of n-MOSFET. For $V_{g}<0$ and $V_{d}<0$, the behavior of $I_{d}-V_{d}$ curves were similar to that of p-MOSFET. Thus, the bipolar property of CNTNFET synthesized by ACCVD and using $\mathrm{HfO}_{2}$ as top-gate dielectric was demonstrated.

Figure 7 shows the output characteristics, drain current versus gate voltage $\left(I_{d}-V_{g}\right)$, of (a) p-CNTNFET and (b) nCNTNFET with an $\mathrm{HfO}_{2}$ of $30 \mathrm{~nm}$ as gate dielectric. The results suggest that both p-CNTNFET and n-CNTNFET exhibits an on-to-off ratio of $\sim 10^{6}$ and a threshold voltage of -3 and $2.6 \mathrm{~V}$, respectively. To estimate the effective hole and electron mobility in p-CNTNFET and n-CNTNFET, respectively, the following formula is adopted [16]:

$$
\mu_{\text {eff }}=\frac{d I_{d}}{d V_{g}} \cdot \frac{t_{\mathrm{ox}} \cdot L}{\varepsilon_{\mathrm{ox}} \cdot V_{d} \cdot W}
$$

where $t_{\mathrm{ox}}$ is the equivalent oxide thickness (EOT) of $\mathrm{HfO}_{2}$ gate, dielectric and $\varepsilon_{0 x}$ is the permittivity of the silicon dioxide. $L$ and $W$ are the channel length and the channel width of CNTNFETs. For these networks, the effective hole mobility of $1.7 \times 10^{3} \mathrm{~cm}^{2} / \mathrm{V}$-s for the p-CNTNFET and the effective electron mobility of $3.2 \times 10^{2} \mathrm{~cm}^{2} / \mathrm{V}$-s for the n-CNTNFET were extracted, respectively. To estimate 

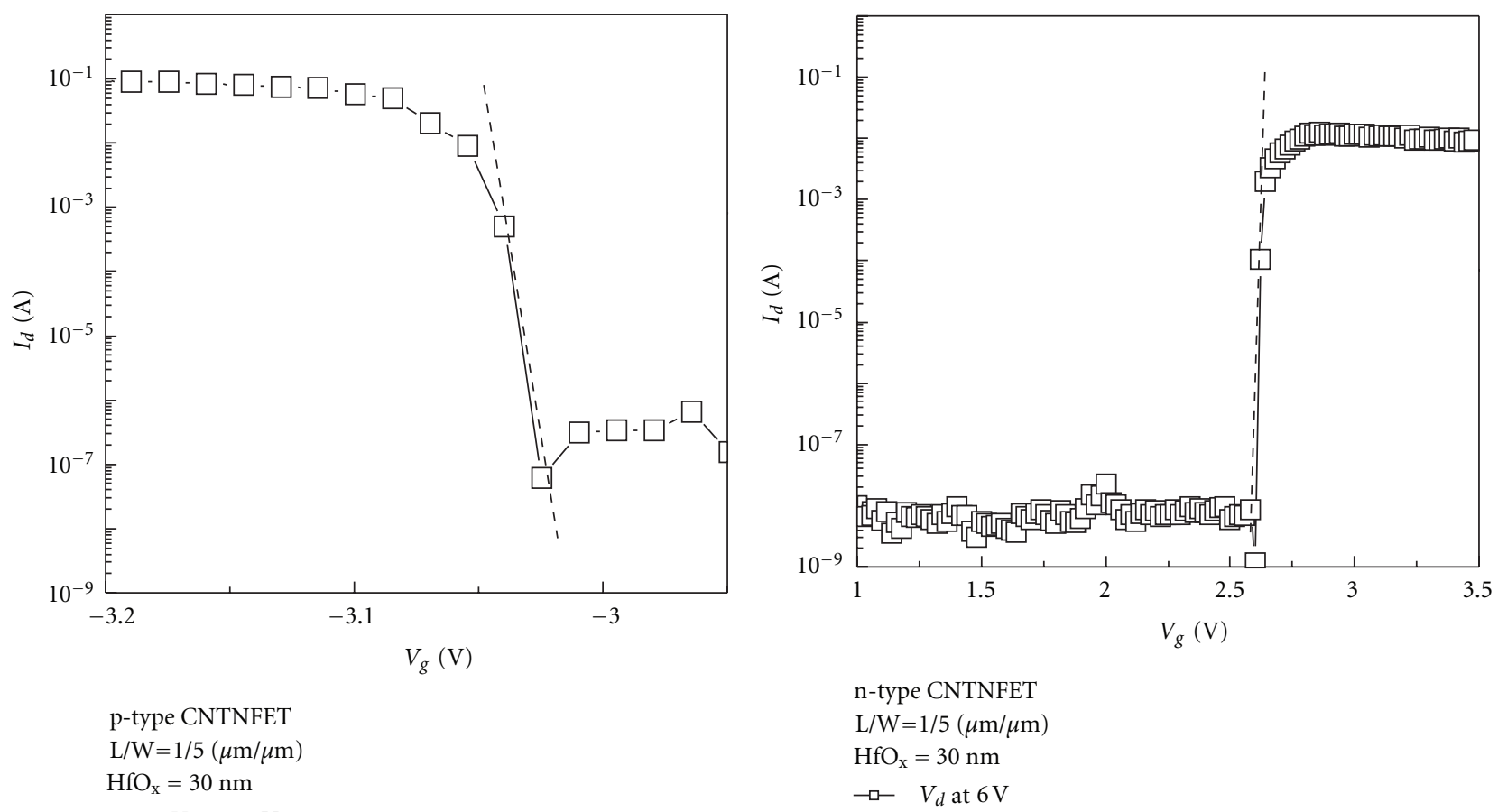

(a)

(b)

FIGURE 7: Drain current versus gate voltage $\left(I_{d}-V_{g}\right)$ characteristics of (a) p-CNTNFET and (b) n-CNTNFET with an $\mathrm{HfO}_{2}$ of 30 nm as gate dielectric. The channel length and width of CNTNFETs were 1 and $5 \mu \mathrm{m}$, respectively.

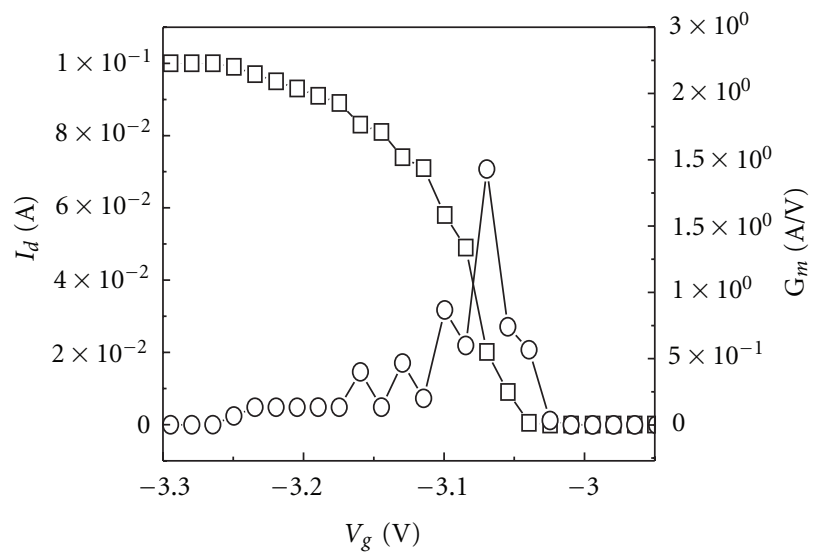

$$
\begin{aligned}
& \text { p-type CNTNFET } \\
& \mathrm{L} / \mathrm{W}=1 / 5(\mu \mathrm{m} / \mu \mathrm{m}) \\
& \mathrm{HfO}_{\mathrm{x}}=30 \mathrm{~nm} \\
& \multimap-V_{d}=-6 \mathrm{~V} \\
& \multimap-\mathrm{G}_{m}(\mathrm{~A} / \mathrm{V})
\end{aligned}
$$

(a)

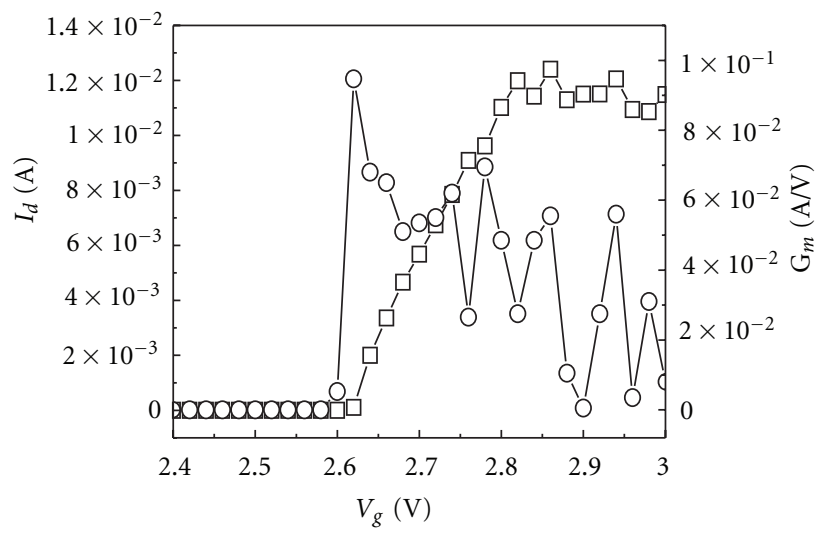

n-type CNTNFET

$\mathrm{L} / \mathrm{W}=1 / 5(\mu \mathrm{m} / \mu \mathrm{m})$

$\mathrm{HfO}_{\mathrm{x}}=30 \mathrm{~nm}$

$\rightarrow-V_{d}=6 \mathrm{~V}$

$\multimap \mathrm{G}_{m}(\mathrm{~A} / \mathrm{V})$

FIgURE 8: The output characteristic transconductance $\left(G_{m}\right)$ of $\mathrm{HfO}_{2}$-gated (a) p-CNTNFET and (b) n-CNTNFET.

the subthreshold slope (SS) in both p-CNTNFET and nCNTNFET, the following formula is adopted [20]:

$$
S S=\left[\frac{d \log I_{d}}{d V_{g}}\right]^{-1} .
$$

The results show that the $S S$ of $6 \mathrm{mV} /$ decade for the pCNTNFET and the $S S$ of $18 \mathrm{mV} /$ decade for the $\mathrm{n}$-CNTNFET were extracted, respectively. In general, the SS characteristics of the conventional silicon-based MOSFET is to be around 70-100 mV/decade [20]. Thus, the SS characteristics of 
CNTNFETs synthesized by ACCVD is better than that of the silicon-based MOSFET one. To demonstrate the amplifier characteristics, the transconductance output characteristics $\left(G_{m}\right)$ of $\mathrm{HfO}_{2}$-gated p-CNTNFET and n-CNTNFET were shown in Figure 8. The results show that the $G_{m}$ of $1.93 \mathrm{~A} / \mathrm{V}$ for the p-CNTNFET and the $G_{m}$ of $0.095 \mathrm{~A} / \mathrm{V}$ for the $\mathrm{n}$-CNTNFET were extracted, indicating that the amplifier characteristics of p-CNTNFET is better than that of nCNTNFET one.

\section{Conclusions}

The present study gives an important message that the bipolar property of semiconducting single-walled CNTNFET synthesized by ACCVD and using $\mathrm{HfO}_{2}$ as topgate dielectric was demonstrated. The densities of CNTNs increase with increasing process temperature, treated time, and $\mathrm{Co} / \mathrm{Mo}$ catalysts concentrations. Experimental results indicate that the random networks of SWNTs with higher effective hole/electron mobility, smaller subthreshold slope, are the promising candidate for the development of the nano-electronic devices.

\section{Acknowledgments}

The authors would like to thank the National Science Council of Taiwan for the financial support under Contract no. NSC 99-2221-E-224-020 and NSC 99-2622-E-150-032-CC3. Technical support from National Nano Device Laboratories (NDL) of Taiwan and common Laboratories for Micro/Nano Science and Technology of National Formosa University are also acknowledged.

\section{References}

[1] S. J. Wind, J. Appenzeller, R. Martel, V. Derycke, and P. Avouris, "Vertical scaling of carbon nanotube field-effect transistors using top gate electrodes," Applied Physics Letters, vol. 80, no. 20, pp. 3817-3819, 2002.

[2] V. Derycke, R. Martel, J. Appenzeller, and P. Avouris, "Controlling doping and carrier injection in carbon nanotube transistors," Applied Physics Letters, vol. 80, no. 15, pp. 27732775, 2002.

[3] B. H. Chen, H. C. Lin, T. Y. Huang et al., "Complementary carbon nanotube-gated carbon nanotube thin-film transistor," Applied Physics Letters, vol. 88, no. 9, Article ID 093502, 2006.

[4] P. G. Collins, M. S. Arnold, and P. Avouris, "Engineering carbon nanotubes and nanotube circuits using electrical breakdown," Science, vol. 292, no. 5517, pp. 706-709, 2001.

[5] P. L. McEuen, M. S. Fuhrer, and H. Park, "Single-walled carbon nanotube electronics," IEEE Transactions on Nanotechnology, vol. 1, no. 1, pp. 78-84, 2002.

[6] S. Rosenblatt, Y. Yaish, J. Park, J. Gore, V. Sazonova, and P. L. McEuen, "High performance electrolyte gated carbon nanotube transistors," Nano Letters, vol. 2, no. 8, pp. 869-872, 2002.

[7] Z. Yao, C. L. Kane, and C. Dekker, "High-field electrical transport in single-wall carbon nanotubes," Physical Review Letters, vol. 84, no. 13, pp. 2941-2944, 2000.
[8] S. Heinze, J. Tersoff, R. Martel, V. Derycke, J. Appenzeller, and P. Avouris, "Carbon nanotubes as Schottky barrier transistors," Physical Review Letters, vol. 89, no. 10, Article ID 106801, pp. 1-4, 2002.

[9] A. Bachtold, P. Hadley, T. Nakanishi, and C. Dekker, "Logic circuits with carbon nanotube transistors," Science, vol. 294, no. 5545, pp. 1317-1320, 2001.

[10] Y. Zhang, A. Chang, J. Cao et al., "Electric-field-directed growth of aligned single-walled carbon nanotubes," Applied Physics Letters, vol. 79, no. 19, pp. 3155-3157, 2001.

[11] K. J. Lee, H. M. So, B. K. Kim et al., "Single nucleotide polymorphism detection using Au-decorated single-walled carbon nanotube field effect transistors," Journal of Nanomaterials, vol. 2011, Article ID 105138, 8 pages, 2011.

[12] H. Oh, J. J. Kim, W. Song et al., "Fabrication of $\mathrm{n}$-type carbon nanotube field-effect transistors by Al doping," Applied Physics Letters, vol. 88, no. 10, Article ID 103503, 2006.

[13] T. Dürkop, S. A. Getty, E. Cobas, and M. S. Fuhrer, "Extraordinary mobility in semiconducting carbon nanotubes," Nano Letters, vol. 4, no. 1, pp. 35-39, 2004.

[14] ITRS, International Technology Roadmap of Semiconductor 2009 edition, http://www.itrs.net/.

[15] A. M. Cassell, G. C. McCool, H. T. Ng et al., "Carbon nanotube networks by chemical vapor deposition," Applied Physics Letters, vol. 82, no. 5, pp. 817-819, 2003.

[16] E. S. Snow, J. P. Novak, P. M. Campbell, and D. Park, "Random networks of carbon nanotubes as an electronic material," Applied Physics Letters, vol. 82, no. 13, pp. 2145-2147, 2003.

[17] U. J. Kim, E. H. Lee, J. M. Kim, Y. S. Min, E. Kim, and W. Park, "Thin film transistors using preferentially grown semiconducting single-walled carbon nanotube networks by water-assisted plasma-enhanced chemical vapor deposition," Nanotechnology, vol. 20, no. 29, Article ID 295201, 2009.

[18] A. Jorio, M. A. Pimenta, A. G. Souza Filho, R. Saito, G. Dresselhaus, and M. S. Dresselhaus, "Characterizing carbon nanotube samples with resonance Raman scattering," New Journal of Physics, vol. 5, article 139, pp. 1-17, 2003.

[19] A. Jorio, A. G. Souza Filho, G. Dresselhaus et al., "G-band resonant Raman study of 62 isolated single-wall carbon nanotubes," Physical Review B, vol. 65, no. 15, Article ID 155412, pp. 1-9, 2002.

[20] S. M. Sze, Semiconductor Devices: Physics and Technology, John Wiley \& Sons, New York, NY, USA, 1985. 

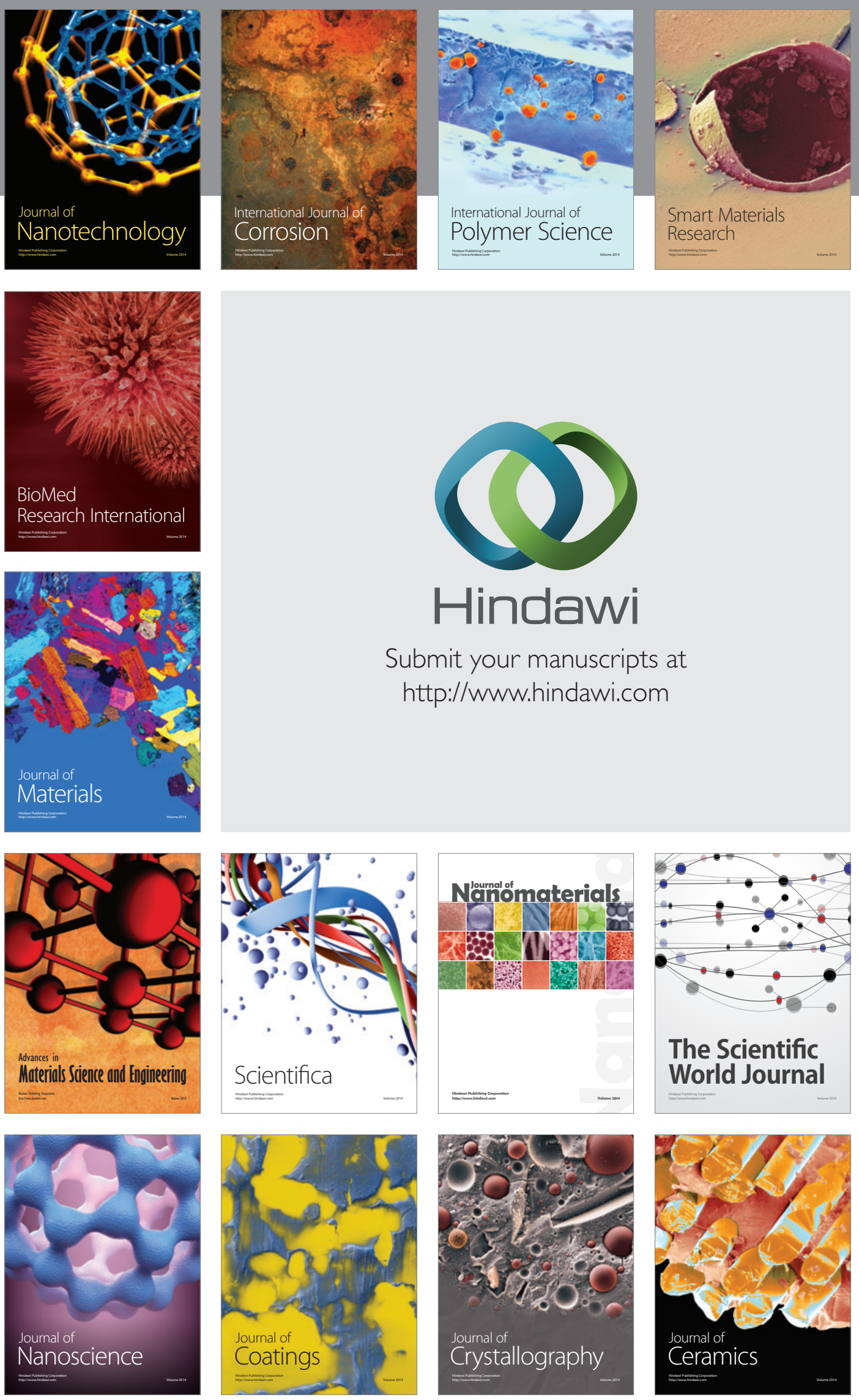

The Scientific World Journal

Submit your manuscripts at

http://www.hindawi.com

\section{World Journal}

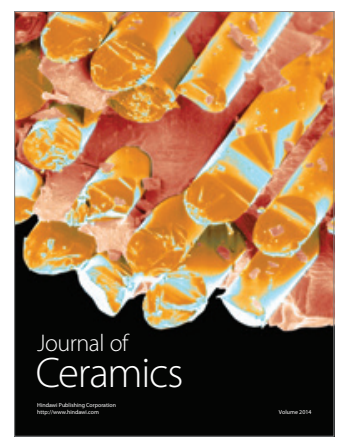

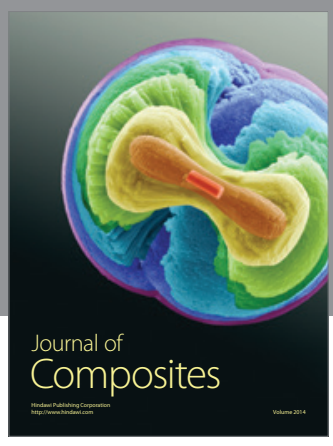
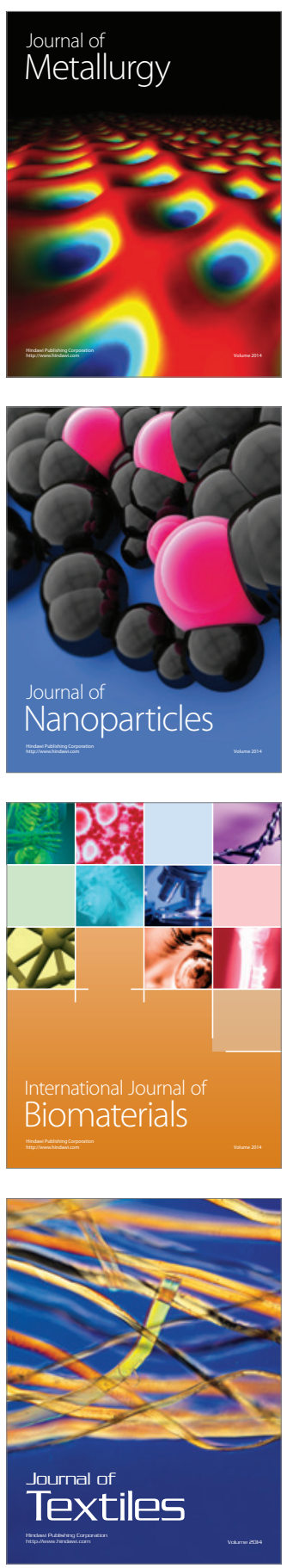